Submission ID: 43815

\title{
Development of Fractured Zones of Khadum Suite Deposits in East
} Caucasian Region

A.S. Rakhmatullina (Gubkin Russian State University of Oil and Gas), A. Postnikov (Gubkin Russian State University of Oil and Gas), L. Miloserdova (Gubkin Russian State University of Oil and Gas), O. Sivalneva (Gubkin Russian State University of Oil and Gas), A. Musikhin (Gubkin Russian State University of Oil and Gas), Y. Varov* (Gubkin Russian State University of Oil and Gas), I. Sabirov (Gubkin Russian State University of Oil and Gas)

\section{SUMMARY}

The Pre-Caucasian Oil and Gas Province is one of the oldest provinces in Russia, the main hydrocarbon reserves are associated with the Meso-Cenozoic sedimentary complex. Unlike the Mesozoic sedimentary complex, which is mainly represented by fractured-porous and porous reservoirs in terrigenous and carbonate rocks, the prospects of the Cenozoic sedimentary complex are associated with clayey porousfractured Paleogene reservoirs, including reservoirs in the deposits of the Khadum suite of the Early Paleogene.

Since the fractured component has a key role in the structure of the reservoir and in the filtration of fluids, it is necessary to develop a technique for developing of decompaction zones which are perspective to have a fractured reservoirs in the deposits of the Khadum suite, based on the complex of geological, geophysical and remote methods. 


\section{Выделение зон трещиноватости в отложениях хадумской свиты Восточного Предкавказья}

А.С. Рахматуллина*, А.В. Постников, Л.В. Милосердова, О.В. Сивальнева, А.Д. Мусихин, Ю.Е. Варов, И.А. Сабиров (РГУ нефти и газа (НИУ) имени И.М. Губкина)

\section{Введение}

Предкавказская НГП - одна из старейших провинций России, основные запасы углеводородов которой связаны с мезо-кайнозойским осадочным комплексом. В отличие от мезозойского осадочного комплекса, представленного, в основном, трещинно-поровыми и поровыми коллекторами в терригенных и карбонатных породах, перспективы кайнозойского осадочного комплекса связаны с глинистыми порово-трещинными коллекторами палеогена, в том числе в отложениях хадумской свиты раннего палеогена.

Так как трещинная составляющая играет ключевую роль в строении коллектора и в фильтрации флюидов, необходимо разработать методику выделения зон разуплотнения, перспективных для развития трещинных коллекторов в отложениях хадумской свиты, по комплексу геолого-геофизических и дистанционных методов.

\section{Метод}

В условиях недостатка кернового материала и ограниченного количества литологических данных и данных ГИС, выделение зон развития трещиноватости может производиться по комплексу данных сейсморазведки и интерпретации результатов дистанционных методов, в том числе линеаментного анализа на основе космо-геологического дешифрирования.

В основу выделения разломно-блоковых структур и связанных с ними зон трещиноватости положен анализ разломно-блоковой тектоники современной земной поверхности на основе космо- и топогеологического дешифрирования. В результате такого дешифрирования выделяются линеаменты, которые представляют собой линейно вытянутые элементы рельефа/земной коры, длина которых много больше их ширины (раскрытости), геологическая позиция которых отражает внутреннюю неоднородность литосферы [Кац Я.Г. и др, 1986].

Моделирование разломно-блоковой структуры рассматриваемой территории основано на представлении о блоковом строении фундамента и существовании нескольких взаимоортогональных систем ФРН, образующих единую сеть [Шульц С.С., 1986].

Высокой степени детализации дешифрирования способствовало наличие разветвленной гидрографической сети и высокая контрастность топографического плана. К сожалению, значительное антропогеновое воздействие на природные ландшафты не позволило закартировать всю совокупность линеаментов, отражающих элементы различных систем линеаментов.

Флексурно-разрывные нарушения выделяются по данным сейсморазведки, по наличию нарушения осей синфазности прослеживаемых горизонтов на волновом поле, а также по изменениям амплитудно-частотных характеристик вдоль прослеживаемого отражения (интервала) [Тяпкин К.Ф. и др, 1982].

В результате независимых анализов сейсмопрофилей точки выхода разломов отмечаются на дневной поверхности. В случае если предполагаемое нарушение прослеживается на всех профилях, с определённой долей вероятности выделяется флексурно-разрывное нарушение.

Для статистической обработки выделенных визуально (экспертным и компьютерным методом), а также сведенных на одну схему систем линеаментов и осей флексурно-разрывных нарушений использовался пакет компьютерных программ LESSA (Lineament Extraction and Stripe Statistical Analysis), одна из возможностей которых позволяет работать с полученными 
схемами и строить по ним разнообразные карты и схемы статистических характеристик. В данном случае строилась карта плотностей, максимумы которых - «узлы» - приурочены к основным пересечениям систем линеаментов либо осей флексурно-разрывных нарушений.

Наиболее перспективные зоны развития трещиноватости выделяются в местах совпадения максимумов плотностей линеаментов и осей флексурно-разрывных нарушений.

\section{Примеры}

На территории Предкавказья были закартированы 4 диагональные и одна меридиональноширотная взаимоортогональные системы линеаментов. Элементы различных систем развиты в целом неравномерно по территории. Отчетливо прослеживаются зоны их концентрации, отмечается сочетание линеаментов различной протяженности. В целом сгущение линеаментов наблюдается в районе Большого Кавказского Хребта, речных систем, берущих начало в горах Кавказа, а также вдоль крупных речных систем (Волги, Дона) и акваторий внутриконтинентальных морей (Азовского, Чёрного, Каспийского).

Не вызывает сомнений, что столь крупные приповерхностные неоднородности должны в какой-то мере отражаться и в глубинном строении. На основании этого можно сделать предположение о связи наблюдаемых структур с глубокими уровнями как осадочного чехла, так и фундамента [Г.И. Амурский и др, 1988].

Выделение поверхностных структур может рассматриваться как косвенный метод определения зон разуплотнения; для выделения же осей флексурно-разрывных нарушения и оценки степени их плотности используется комплексирование материалов дистанционных съемок и данных сейсморазведки. Интерпретация данных площадной сейсморазведки позволила сопоставить элементы наблюдаемых систем линеаментов с данными интерпретации сейсмических материалов, что позволило ранжировать разломно-блоковые структуры (оси флексурноразрывных зон) по степени выраженности на глубинах, соответствующих хадумской свите, трассировать их как по латерали, так и в разрезе, и, в ряде случаев, детализировать их геологическую позицию.

В отличие от сложно дифференцированной в структурном отношении поверхности фундамента, тектоническое строение региона по отдельным стратиграфическим комплексам осадочного чехла в значительной степени упрощается, при этом темп сглаживания очертаний тектонических элементов возрастает вверх по разрезу осадочного чехла, переходя во флексурно-разрывные нарушения. Выделенные разломы в целом имеют ту же направленность, что и выделенные ранее системы линеаментов, образуя зоны повышенной трещиноватости. Преобладают разломы меридионально-широтной направленности и северо-запад - юговосточной направленности. Выделенные региональные нарушения высокого ранга и их ориентировка в целом соответствуют границам структурно-тектонических зон.

Места наибольших плотностей линеаментов и осей флексурно-разрывных нарушений, определённые с помощью программного комплекса LESSA, наблюдаются вдоль Большого Кавказского хребта, и их простирание в целом совпадает с простиранием Большого Кавказского хребта. Также сгущение линеаментов происходит вдоль русла реки Калаус (меридионального простирания), реки Кума (юго-восточного простирания), по побережьям Чёрного, Азовского и Каспийского морей (северо-восточного простирания). Наименьшие плотности линеаментов определены в равнинной части Предкавказья (Рисунок 1$)$.

Перспективные зоны развития трещинных коллекторов выделяются при сопоставлении участков максимальных плотностей линеаментов и осей флексурно-разрывных нарушений, исходя из представлений о том, что места наибольшей концентрации нарушений соответствуют местам развития трещиноватости, при этом наиболее перспективными зонами являются места совпадения максимумов и тех, и других (Рисунок 2). Не вызывает сомнений влияние трещиноватости на работу скважин, совместно с другими типами пустот отложений хадумской свиты [А.В. Постников и др, 2016], [А.Д. Мусихин, 2017]. 

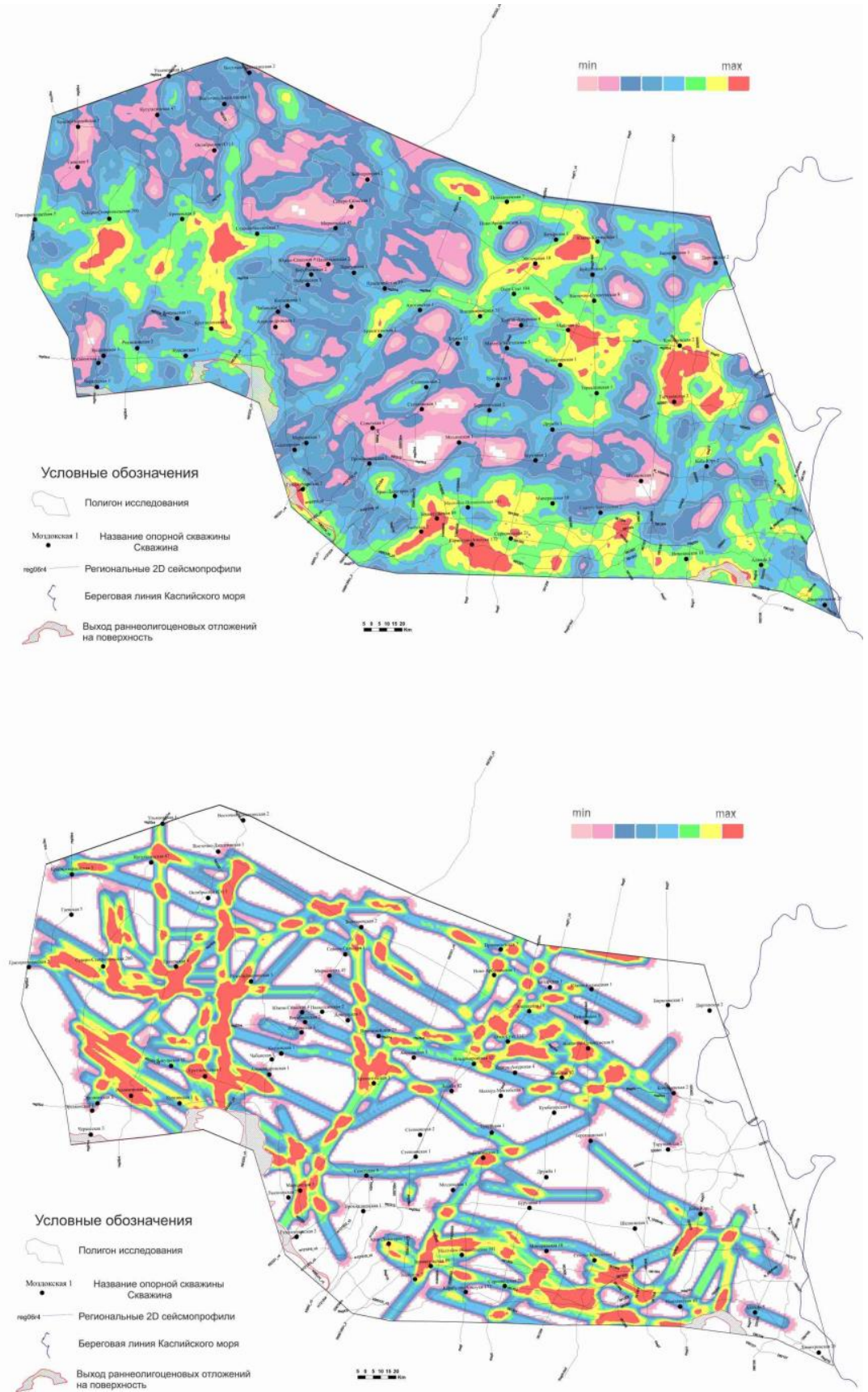

Рисунок 1 Плотности линеаментов (наверху) и осей флексурно-разрывных нарушений (внизу)

Следует учитывать минеральный состав пород хадумской свиты, так как наибольшей хрупкостью обладают породы с повышенным содержанием кремнистой и карбонатной компонент [О.В. Сивальнева и др., 2016].

\section{Выводы}

Существенную роль в строении коллекторов и обеспечении проницаемости хадумских отложений играет трещиноватость. Зоны развития трещиноватости приурочены, как правило, к осевым частям крупных нарушений, выделяемых по комплексу геолого-геофизических и дистанционных методов. Определение областей трещиноватости определяется по плотности нарушений. В условиях недостатка данных бурения комплексирование геолого-геофизических данных позволяет весьма уверенно выделять зоны трещиноватости. 


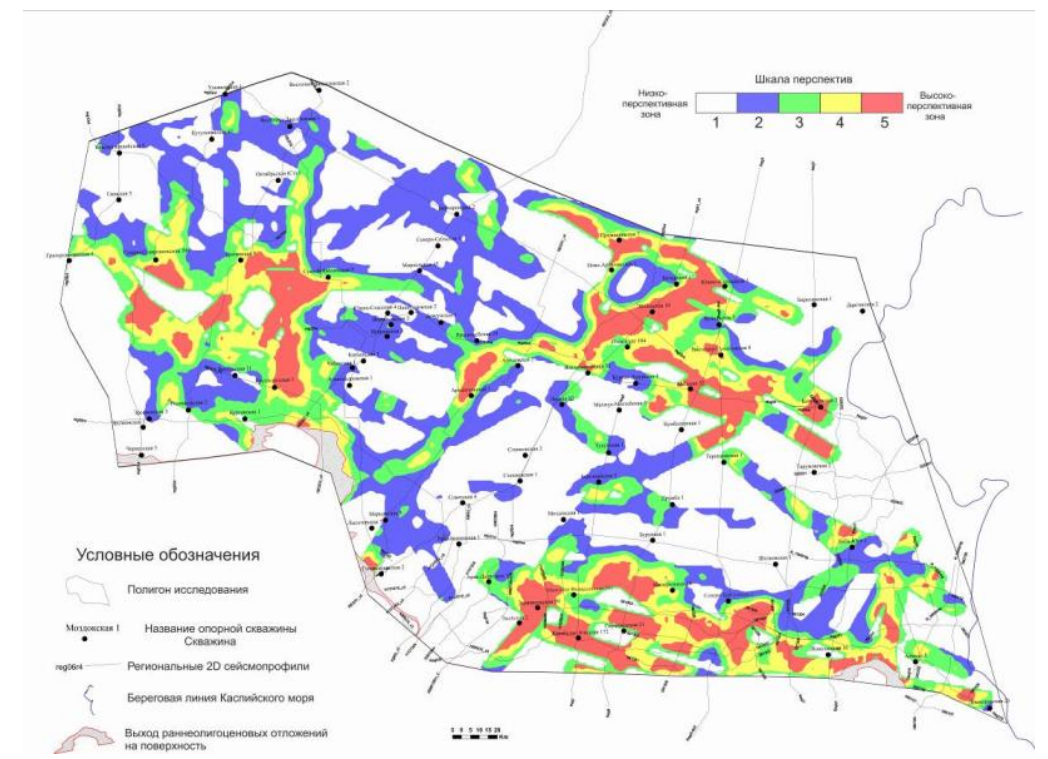

Рисунок 2 Перспективные зоны развития трещинных коллекторов

\section{Благодарности}

Авторы выражают благодарность заведующему кафедрой разведочной геофизики и компьютерных систем, д.т.н., проф. В.И. Рыжкову, доценту кафедры литологии, к.г.-м.н., доц. Н.А. Осинцевой, ведущему научному сотруднику ИФЗ имени О.Ю. Шмидта РАН, д.г.-м.н. Л.А. Сим.

\section{Библиография}

А.В. Постников, А.Д. Мусихин, Н.А. Осинцева, О.В. Сивальнева, А.С. Рахматуллина. Влияние структуры пустотного пространства пород на разработку залежей в хадумских отложениях Восточного Предкавказья. Геофизика, 6, 2016, с 30-37.

А.Д. Мусихин, А.В. Постников, Ю.В. Ляпунов, Н.А. Осинцева, О.В. Сивальнева, А.С. Рахматуллина, О.А. Антипова, И.А. Сабиров. Связь пустотного пространства пород с разработкой залежей УВ в хадумских отложениях Восточного Предкавказья. Тезисы совместного семинара EAGE/SPE 2017 наука о сланцах: Проблемы разведки и разработки. Москва, 10-11 апреля 2017 г.

Г.И. Амурский, Г.А. Абраменок, М.С. Бондарева, Н.Н. Соловьёв. Дистанционные методы изучения тектонической трещиноватости пород нефтегазоносных территорий - М.: Недра, 1988. - 164 с.: ил.

Кац Я.Г., Полетаев А.И., Румянцева Э.Ф. Основы линеаментой тектоники. - М.: Недра, 1986. 140 с., с ил.

О.В. Сивальнева, Н.А. Осинцева, А.В. Постников, Ю.Е. Варов, В.В. Пошибаев, М.Р. Ганаева. Литологическая характеристика и строение разрезов хадумских отложений Восточного Предкавказья. Геофизика, 6, 2016, с 14-20.

Тяпкин К.Ф., Кивелюк Т.Т. Изучение разломных структур геолого-геофизическими методами. М.: Недра, 1982. 240 с.

Шульц С.С. Планетарная трещиноватость/Планетарная трещиноватость. Л.: Издательство ЛГУ, 1973. С. 5-37. 


\section{References}

A.V. Postnikov, A.D. Musikhin, N.A. Osintseva, O.V. Sivalneva, A.S. Rakhmatullina. Vliyaniye struktury pustotnogo prostranstva porod na razrabotku zalezhey $\mathrm{v}$ khadumskikh otlozheniyakh Vostochnogo Predkavkazya. Geofizika, 6, 2016, s 30-37

A.D. Musikhin, A.V. Postnikov, YU.V. Lyapunov, N.A. Osintseva, O.V. Sivalneva, A.S. Rakhmatullina, O.A. Antipova, I.A. Sabirov. Svyaz pustotnogo prostranstva porod s razrabotkoy zalezhey UV v khadumskikh otlozheniyakh Vostochnogo Predkavkazya. Tezisy sovmestnogo seminara EAGE/SPE 2017 nauka o slantsakh: Problemy razvedki i razrabotki. Moskva, 10-11 aprelya $2017 \mathrm{~g}$.

G.I. Amurskiy, G.A. Abramenok, M.S. Bondareva, N.N. Solovyov. Distantsionnyye metody izucheniya tektonicheskoy treshchinovatosti porod neftegazonosnykh territoriy - M.: Nedra, 1988. 164 s.: il.

Kats YA.G., Poletayev A.I., Rumyantseva E.F. Osnovy lineamentoy tektoniki. - M.: Nedra, 1986. 140 s., s il.

O.V. Sivalneva, N.A. Osintseva, A.V. Postnikov, YU.Ye. Varov, V.V. Poshibayev, M.R. Ganayeva. Litologicheskaya kharakteristika i stroyeniye razrezov khadumskikh otlozheniy Vostochnogo Predkavkaz'ya. Geofizika, 6, 2016, s 14-20.

Tyapkin K.F., Kivelyuk T.T. Izucheniye razlomnykh struktur geologo-geofizicheskimi metodami. M.: Nedra, 1982. $240 \mathrm{~s}$.

Shults S.S. Planetarnaya treshchinovatost//Planetarnaya treshchinovatost. L.: Izdatel'stvo LGU, 1973. S. 5-37. 